\title{
Silent somatotroph tumour revisited from a study of 80 patients with and without acromegaly and a review of the literature
}

\author{
Laura Chinezu', Alexandre Vasiljevic 2,3, Jacqueline Trouillas ${ }^{2,3}$, Marion Lapoirie ${ }^{2,4}$, \\ Emmanuel Jouanneau ${ }^{2,5,6}$ and Gérald Raverot ${ }^{2,4,5}$ \\ 'Department of Histology, University of Medicine and Pharmacy, Tirgu Mures, Romania, ${ }^{2}$ Faculté de \\ Médecine Lyon-Est, Université Lyon 1, Lyon, France, ${ }^{3}$ Centre de Pathologie et de Biologie Est and \\ ${ }^{4}$ Fédération d'Endocrinologie, Groupement Hospitalier Est, Hospices Civils de Lyon, Bron, France, \\ ${ }^{5}$ INSERM U1052; CNRS UMR5286; Cancer Research Center of Lyon, Lyon, France, and ' ${ }^{6}$ Service de \\ Neurochirurgie, Groupement Hospitalier Est, Hospices Civils de Lyon, Bron, France
}

\author{
Correspondence \\ should be addressed \\ to G Raverot \\ Email \\ gerald.raverot@chu-lyon.fr
}

\section{Abstract}

Background: Silent somatotroph tumours are growth hormone (GH) immunoreactive (IR) pituitary tumours without clinical and biological signs of acromegaly. Their better characterisation is required to improve the diagnosis. Materials and methods: Twenty-one silent somatotroph tumours were compared to 59 somatotroph tumours with acromegaly. Tumours in each group were classified into $\mathrm{GH}$ and plurihormonal (GH/prolactin (PRL)/ \pm thyroidstimulating hormone (TSH)) and into densely granulated (DG) and sparsely granulated (SG) types. The two groups were then compared with regards to proliferation (Ki-67, p53 indexes and mitotic count), differentiation (expression of somatostatin receptors SSTR $2 \mathrm{~A}-\mathrm{SSTR}_{5}$ and transcription factor Pit-1) and secretory activity ( $\%$ of GH- and PRL-IR cells).

Results: The silent somatotroph tumours represented $2 \%$ of all tested pituitary tumours combined. They were more frequent in women than in men $(P=0.002)$, more frequently plurihormonal and SG $(P<0.01)$, with a lower percentage of GH-IR cells $(P<0.0001)$ compared to those with acromegaly. They all expressed SSTR SA , SSTR 5 and Pit-1. The plurihormonal (GH/PRL/ \pm TSH) tumours were mostly observed in women (sex ratio: $3 / 1)$ and in patients who were generally younger than those with acromegaly $(P<0.001)$. They were larger $(P<0.001)$ with a higher Ki-67 index ( $P=0.007)$.

Conclusions: The silent somatotroph tumours are not uncommon. Their pathological diagnosis requires the immunodetection of $\mathrm{GH}$ and Pit-1. They are more frequently plurihormonal and more proliferative than those with acromegaly. A low secretory activity of these tumours might explain the normal plasma values for $\mathrm{GH}$ and insulin-like growth factor 1 (IGF1) and the absence of clinical signs of acromegaly.

\section{Introduction}

Silent pituitary tumours represent hormoneimmunoreactive (IR) tumours without clinical signs of hormone excess $(1,2)$. They are included in the group of non-functioning tumours without signs of hypersecretion, which represent around $30 \%$ of all pituitary tumours, the most common being the follicle stimulating/luteinizing (c) 2017 European Society of Endocrinology Printed in Great Britain
European Journal of Endocrinology

(2017) 176, 195-201 
The somatotroph tumours without clinical signs of acromegaly were first described to exhibit high plasma levels of growth hormone (GH) $(2,4,5)$. In a later series of 17 patients described a few years later (6), two groups of patients could be defined: one with high plasma GH levels and the other with normal values. This later study also underlined a greater frequency of GH-prolactin (PRL) tumours compared to those with acromegaly. More recently, the fact that some 'silent' somatotroph tumours are 'more quiet than silent' (7) or are clinically silent but with elevated insulin-like growth factor 1 (IGF1) has been stressed (8). Elsewhere, pituitary pathologists have described a new 'silent subtype-3 pituitary adenoma' based on ultrastructural features $(9,10)$. Originally classified as a variant of silent corticotroph adenoma, this subtype is now considered as a plurihormonal tumour of the Pit-1 lineage that is mainly positive for $\mathrm{GH}, \mathrm{PRL} \pm$ thyroidstimulating hormone (TSH) and not always silent, being sometimes associated with hyperthyroidism, acromegaly or amenorrhoea-galactorrhoea (AG). It was thus since recently classified as being a poorly differentiated monomorphous plurihormonal Pit-1 lineage adenoma (11). The nomenclature has become very confusing and needs careful clarification, especially in the light of reports of such silent somatotroph or plurihormonal tumours being aggressive $(10,11)$ and the suggestions for the need to treat affected patients differently from those with acromegaly. In an attempt to clarify these issues, here in this study, we address two questions: (1) Do 'true' silent somatotroph tumours exist and what is their prevalence? (2) Do the silent mono or plurihormonal somatotroph tumours differ from the same immunohistochemical subtype with acromegaly and is the silent plurihormonal subtype identical to the silent type 3 adenoma?

To answer these questions, we conducted a comparative retrospective study of 21 somatotroph tumours from patients without clinical and hormonal signs of acromegaly and 59 somatotroph tumours from those with acromegaly.

\section{Subjects and methods}

\section{Selection of patients and clinical data}

From our tissue bank of pituitary tumours, we listed all the patients operated on by two neurosurgeons, experts in pituitary surgery, between 1990 and 2015 at the Hôpital Neurologique, Hospices Civils de Lyon, France. Thirtyfive patients with somatotroph tumours were referred directly to the neurosurgeon for symptoms of mass effect.
Medical records were retrospectively reviewed with respect to symptoms at presentation, neuroimaging characteristics and preoperative endocrine status. Fourteen patients were excluded for lack of preoperative data concerning the GH and IGF1 plasma levels or due to elevated plasma values according to their sex and age. Twenty-one patients without signs of acromegaly and with normal IGF1 plasma levels (according to age-matched reference values) at diagnosis were considered to have silent somatotroph tumours and were included in this study. Among the 16 tumours expressing prolactin, the prolactin level was normal in $9(<25 \mu \mathrm{g} / \mathrm{L})$ or slightly elevated and compatible with pituitary stalk compression $(<150 \mu \mathrm{g} / \mathrm{L})$ in 7 patients. Post-operative data were available for 19 patients, but long-term follow-up was available for 15 patients only (median 6 years, 1.0-20 years). They were compared to 59 randomly selected patients with somatotroph tumours, referred for typical acromegaly with clinical and biological signs of hypersecretion. For each of the 80 included patients, their age, sex, clinical signs of acromegaly, MRI aspect (size of the tumour and invasion) and preoperative GH, IGF1 and PRL levels were evaluated.

\section{Pathological data}

All 80 tumours were obtained from the Laboratoire d'Histologie et d'Embryologie Moléculaires, Faculté de Médecine Lyon-EST and the Centre de Pathologie et de Biologie Est, Hospices Civils de Lyon, France.

Fifty-one tumours were fixed in Bouin-Hollande solution and 29 tumours in zinc-formalin solution. For routine histology, haematoxylin phloxine saffron (HPS) and Herlant's tetrachrome staining were performed. The diagnosis of somatotroph tumour was based on automated immunohistochemistry (IHC) reactions with Benchmark XT, Ventana Medical Systems, Tucson, AZ, USA using antibodies against hormones (GH, PRL, adrenocorticotropic hormone (ACTH), $\beta F S H, \beta L H$ and $\beta \mathrm{TSH})$ and against chromogranin $\mathrm{A}(\mathrm{CgA})$ and cytokeratin (CK18). Somatostatin receptors $\left(\mathrm{SSTR}_{2 \mathrm{~A}}\right.$ and $\left.\mathrm{SSTR}_{5}\right)$ and Pit-1 expression were also evaluated. The proliferative rate (mitoses and Ki-67 index) and expression of p53 were also studied. The immunohistochemical reactions with the 5 last antibodies were performed on fresh sections of all tumours simultaneously. Immunoprofiles for each of the antibodies used against the pituitary hormones have been described previously (12). For new antibodies, the references were the following: SSTR $_{2 \mathrm{~A}}$

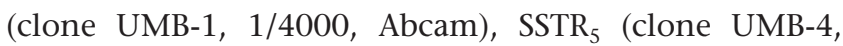
1/500, Abcam) (13) and Pit-1 (1/500, Novus Biologicals 
Europe, Abingdon, UK). The specificity of the anti-Pit-1 antibody was tested on 10 FSH-LH, 5 ACTH and 5 PRL-IR tumours. The reaction was negative against FSH-LH and ACTH but positive against PRL. All the silent tumours and the 29 tumours with acromegaly fixed in zinc-formalin underwent further testing.

The histopathology of all the tumours was characteristic of a somatotroph type with CgA, CK18 and GH immunoreactivity. Based on the staining profile and on the IHC expression of low-weight CK18 either as fibrous body or diffusely distributed in the cytoplasm, the tumours were classified as SG or DG subtypes (14). The CK-negative tumours were classified as SG. The tumours were further classified into monohormonal (GH) and plurihormonal (GH/PRL and GH/PRL/TSH). For the plurihormonal subtype, only tumours with predominant expression of GH-IR cells were considered, and the plurihormonality was diagnosed when the number of PRL or TSH cells was $>5 \%$. Based on the membrane expression and on the percentage of SSTR-IR cells, the tumours were divided into three groups (group 1: $<25 \%$; group 2: $25-75 \%$; group 3: $>75 \%$ ) (13). All the tumours were studied by three pathologists (JT, LC and AV).

For 78 pituitary tumours, data were available for a classification into five grades taking into account invasion and proliferation: grade 1a: non-invasive tumour; grade 1b: non-invasive and proliferative; grade $2 \mathrm{a}$ : invasive tumour; grade $2 \mathrm{~b}$ : invasive and proliferative tumour and grade 3: metastatic tumour (cerebrospinal or systemic metastases) (15). The tumour was considered proliferative with two out of three positive criteria: Ki- $67 \geq 3 \%$, mitoses more than 2/10 HPF and p53 positive (more than 10 strongly positive nuclei/10 HPF). Invasion was considered with histological and/or radiological signs of cavernous or sphenoid sinus invasion.

\section{Statistical analysis}

Statistical analyses were performed using StatView. Data were expressed as means \pm s.E.M. Differences in the proportion were studied with Mann-Whitney test, and continuous variables were compared using $t$ test. $P<0.05$ was considered statistically significant.

\section{Results}

We evaluated the prevalence of silent somatotroph tumours among those informatically registered since 2007 in the Lyon pathological register. Thirteen out of the 21
Table 1 Clinical and pathological data on all somatotroph tumours with and without acromegaly.

\begin{tabular}{|c|c|c|c|}
\hline $\begin{array}{l}\text { Clinical and } \\
\text { pathological data }\end{array}$ & $\begin{array}{l}\text { Tumours with } \\
\text { acromegaly } \\
(n=59) \\
\end{array}$ & $\begin{array}{c}\text { Tumours without } \\
\text { acromegaly } \\
(n=21) \\
\end{array}$ & $P$ value \\
\hline \multicolumn{4}{|l|}{ Clinical data } \\
\hline Sex ratio $(F / M)$ & 23/36 & $17 / 4$ & 0.002 \\
\hline Age (years) & $46.2 \pm 12.4$ & $42.1 \pm 12.6$ & 0.057 \\
\hline Size $(\mathrm{mm})$ & $17.1 \pm 8.6$ & $21.5 \pm 9.7$ & NS \\
\hline Invasion (yes/no) & $30 / 27 *$ & $9 / 12$ & NS \\
\hline \multicolumn{4}{|l|}{ Pathological data } \\
\hline DG/SG & $32 / 27$ & 3/18 & $<0.01$ \\
\hline GH/GH-PRL \pm TSH & $38 / 21$ & $5 / 16$ & $<0.01$ \\
\hline GH (\% of IR cells) & $79.4 \pm 24.5$ & $51.4 \pm 31.2$ & $<0.0001$ \\
\hline PRL (\% of IR cells) & $10.3 \pm 19.5$ & $16.2 \pm 22.4$ & NS \\
\hline Mitoses & $1.4 \pm 2.2$ & $1.1 \pm 1.5$ & NS \\
\hline Ki-67 & $0.9 \pm 1.7$ & $2.3 \pm 2.9$ & 0.052 \\
\hline p53 & $0.6 \pm 0.9$ & $1.3 \pm 1.8$ & NS \\
\hline \multicolumn{3}{|c|}{ Prognostic classification $(n(\%)) * / * *$} & NS \\
\hline Grade 1a & $22(38)$ & $9(43)$ & \\
\hline Grade $1 b$ & $5(9)$ & $3(14)$ & \\
\hline Grade 2a & 21 (37) & $3(14)$ & \\
\hline Grade 2b & $9(16)$ & $6(29)$ & \\
\hline
\end{tabular}

*Data were not available for two tumours. **According to Trouillas et al. (15).

$\mathrm{IR}$, immunoreactive; NS, not significant.

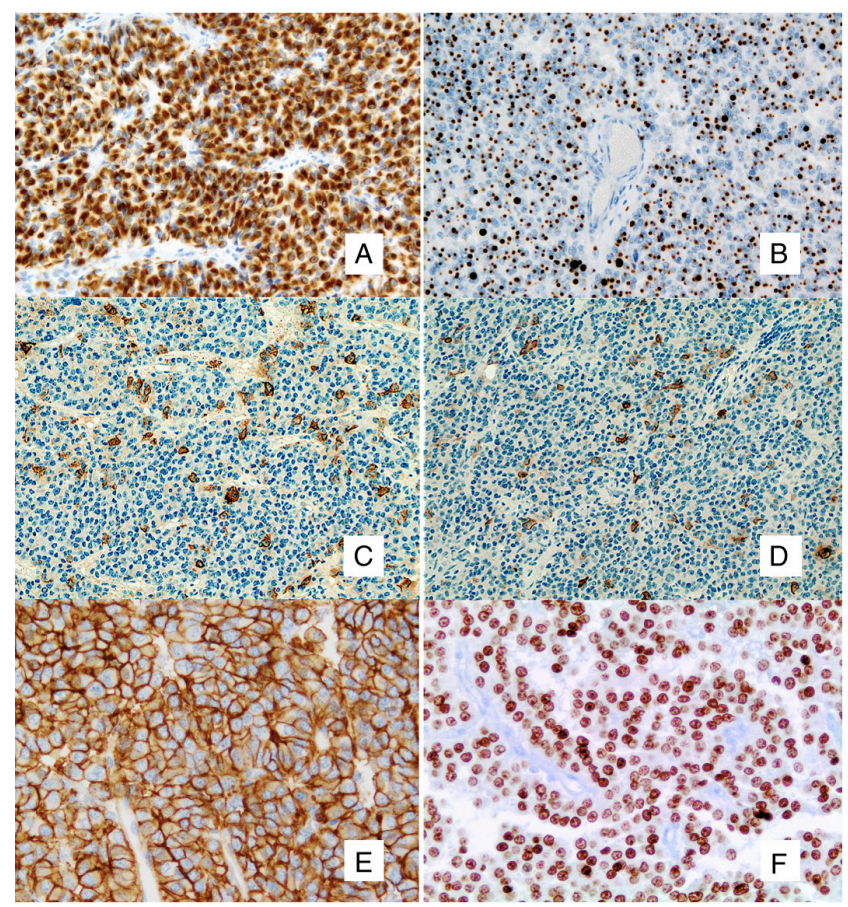

Figure 1

Immunohistochemical expression of cytokeratin (A - diffuse cytoplasmic pattern; B - fibrous body), GH (C - 20\%), PRL (D - 10\%), SSTR $_{2 A}$ (E - group 3: 100\%) and Pit-1 (F-100\%) in silent somatotroph tumours. 
With acromegaly Without acromegaly

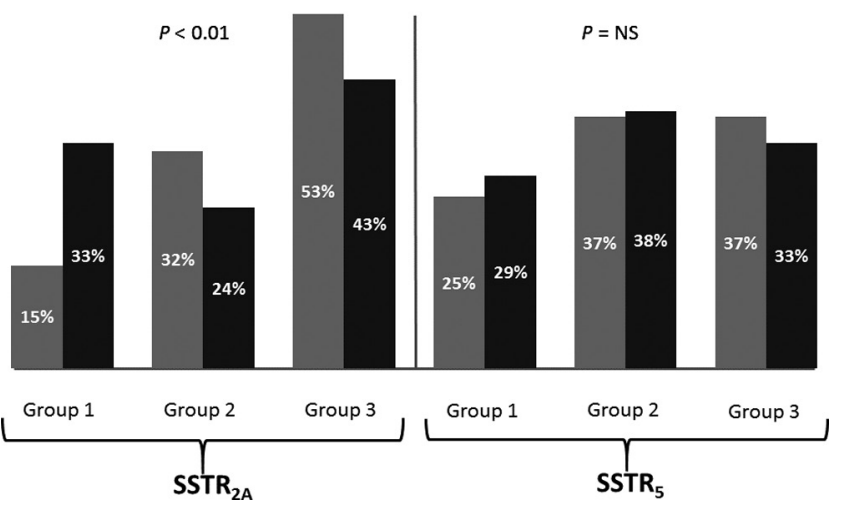

Figure 2

The expression of SSTR $2 \mathrm{~A}-5$ in somatotroph tumours with and without acromegaly.

silent somatotroph tumours of this series were operated on between 2007 and 2015, corresponding to $8 \%$ of all somatotroph tumours and $2 \%$ of all pituitary tumours (13 out of 628).

The silent somatotroph tumours were more frequent in women than in men $(P=0.002)$, whereas a more balanced sex ratio was found among those with acromegaly (Table 1). The mean age at surgery for silent somatotroph tumours tended to be lower, but the difference was not significant $(P=0.057)$. These tumours were diagnosed based on tumour symptoms: mainly headaches, visual troubles, dizziness, amenorrhoea and/or galactorrhoea. All except one were macroadenomas, two of which were giant macroadenomas. However, the two groups showed no statistical difference in terms of the tumour size or percentage of invasive tumours (Table 1).

Histology (Fig. 1 and Table 1) revealed that the silent somatotroph tumours were more frequently SG $(86 \%$ vs $46 \%, P<0.01)$ with a lower percentage of GH-IR cells compared to those with acromegaly $(51.4 \pm 31.2$ vs $79.4 \pm 24.5, P<0.0001)$. The majority were plurihormonal (76\% vs $36 \%, P<0.01)$; almost all were GH/PRL (14/16; 88\%) and 2 were GH/PRL/TSH. Plasma prolactin level was not correlated with PRL expression in plurihormonal tumours. No clinical or biochemical picture of hyperthyroidism was seen in the tumour expressing TSH. None showed immunoreactivity for ACTH, FSH or LH.

Moreover, although $\mathrm{SSTR}_{2 \mathrm{~A}}$ expression was lower in the silent somatotroph tumours, SSTR $_{5}$ expression showed no significant difference between the two groups (Fig. 2). All the tested somatotroph tumours expressed Pit-1 (Fig. 1), mostly with 100\% positive nuclei except for in 5 tumours (all silent) where it was 50-80\%. The two tumour groups showed no significant difference in terms of Ki-67 index, p53 expression or prognostic grades.

Table 2 Clinical and pathological characterisation of plurihormonal somatotroph tumours with and without acromegaly.

\begin{tabular}{|c|c|c|c|c|c|c|}
\hline \multirow[b]{2}{*}{ Clinical and pathological data } & \multicolumn{2}{|c|}{ GH tumours } & \multirow[b]{2}{*}{$P$ value } & \multicolumn{2}{|c|}{ GH/PRL \pm TSH tumours } & \multirow[b]{2}{*}{$P$ value } \\
\hline & $\begin{array}{l}\text { With acromegaly } \\
\qquad(n=38)\end{array}$ & $\begin{array}{l}\text { Without acromegaly } \\
\qquad(n=5)\end{array}$ & & $\begin{array}{l}\text { With acromegaly } \\
\qquad(n=21)\end{array}$ & $\begin{array}{l}\text { Without acromegaly* } \\
\qquad(n=16)\end{array}$ & \\
\hline \multicolumn{7}{|l|}{ Clinical data } \\
\hline Gender (F/M) & $17 / 21$ & $5 / 0$ & 0.048 & $6 / 15$ & $12 / 4$ & 0.008 \\
\hline Age & $45.5 \pm 13.7$ & $52.6 \pm 13.9$ & NS & $47.5 \pm 10.0$ & $38.8 \pm 10.6$ & $<0.001$ \\
\hline Size & $19.3 \pm 9.4$ & $19.3 \pm 6.8$ & NS & $13.0 \pm 4.7$ & $22.2 \pm 10.5$ & $<0.001$ \\
\hline Invasive (yes/no) & $22 / 15 * *$ & $1 / 4$ & NS & $8 / 12 * *$ & $8 / 8$ & NS \\
\hline \multicolumn{7}{|l|}{ Pathological data } \\
\hline DG/SG (\%) & $18 / 20$ & $1 / 4$ & NS & $14 / 7$ & $2 / 14$ & 0.002 \\
\hline GH (\% of IR cells) & $79.9 \pm 28.8$ & $68.0 \pm 43.8$ & NS & $78.6 \pm 14.6$ & $46.2 \pm 25.8$ & $<0.0001$ \\
\hline PRL (\% of IR cells) & - & - & & $28.1 \pm 24.2$ & $21.2 \pm 23.6$ & NS \\
\hline SSTR $_{2 A}$ ( $\%$ of IR cells) & $63.7 \pm 33.3$ & $52.0 \pm 35.6$ & NS & $67.4 \pm 32.8$ & $58.1 \pm 39.4$ & NS \\
\hline $\mathrm{SSTR}_{5}$ ( $\%$ of IR cells) & $54.2 \pm 36.8$ & $62.0 \pm 25.9$ & NS & $51.9 \pm 32.1$ & $49.4 \pm 39.0$ & NS \\
\hline Mitoses & $1.3 \pm 2.4$ & $0.2 \pm 0.4$ & NS & $1.5 \pm 2.0$ & $1.4 \pm 1.6$ & NS \\
\hline Ki-67 & $0.9 \pm 1.9$ & $0.6 \pm 0.8$ & NS & $0.8 \pm 1.2$ & $2.9 \pm 3.2$ & 0.007 \\
\hline p53 & $0.4 \pm 0.7$ & 0 & NS & $0.9 \pm 1.2$ & $1.7 \pm 1.9$ & NS \\
\hline Prognostic classification & & & NS & & & NS \\
\hline Grade 1a & 12 & 4 & & 10 & 5 & \\
\hline Grade 1b & 3 & 0 & & 2 & 3 & \\
\hline Grade 2a & 17 & 1 & & 4 & 2 & \\
\hline Grade $2 b$ & 5 & 0 & & 4 & 6 & \\
\hline
\end{tabular}


Comparing only the 16 plurihormonal silent somatotroph tumours to the 21 plurihormonal with acromegaly, the frequency of this subtype was higher in the silent group than in the group with acromegaly $(76 \%$ vs $36 \% ; P<0.01)$. As shown in Table 2 , the prevalence of women in the silent group was very high $(P=0.008)$ and the tumours were significantly larger $(22.2 \mathrm{~mm}$ vs $13.0 \mathrm{~mm} ; \quad P<0.001)$ even if microadenomas were excluded from the group with acromegaly $(22.2 \mathrm{~mm}$ vs $15.0 \mathrm{~mm} ; P<0.05)$. Out of the 15 patients, 3 underwent adjuvant radiotherapy within the year post-operatively due to the size of the residual tumour and 1 patient presented tumour progression and was treated with gamma knife 6 years after initial surgery. None of the other tumours recurred or progressed during the follow-up period.

By histology, the Ki-67 index was higher compared to those with acromegaly $(P=0.007)$; however, the grades showed no difference. In addition, although all the silent plurihormonal somatotroph tumours were monomorphous and SG $(P=0.002)$, only 6 GH-PRL tumours with acromegaly were mammosomatotroph with most of the remaining having different GH- and PRL-IR cells. The silent plurihormonal somatotroph tumours also showed a lower percentage of GH-IR cells (46.2\% vs $78.6 \%$; $P<0.0001)$. Five out of the 16 silent tumours expressed Pit-1 with a less than 100\% positive nuclei, whereas all the GH/PRL tumours with acromegaly showed maximal expression. Although we found no difference in the pure $\mathrm{GH}$ tumours between the two groups, the number of pure $\mathrm{GH}$ without acromegaly was limited.

\section{Discussion}

In our review of the literature, taking into account the so-called GH silent and the silent type 3 tumours, we found 108 patients $(2,4,5,6,7,8,10,11,16,17,18,19$, $20,21,22,23)$. Almost all were case-reports and only three series including more than 10 patients have been reported $(6,10,11)$. The prevalence of these silent somatotroph tumours as evaluated in this present series is very similar to that evaluated in 1991 (6) (7-8\% of the somatotroph tumours and $2-3 \%$ of all pituitary tumours operated on) and of the silent type 3 (11) (3\%). Thus, silent somatotroph tumours are not uncommon. Indeed, they are as frequent as TSH tumours (2\%).

Many were reported to show signs of hypersecretion $(2,4,5,6,7,11,17,20)$ and only 35 were actually silent. Thus, 'IGF1 should be measured before surgery in all patients presenting with apparently non-functioning adenomas' $(24,25)$.

None of these studies except for our previous one (6) has compared silent to somatotroph tumours with acromegaly. The present study has confirmed our previous data and highlights that silent somatotroph tumours appear more frequently in women than in men, whereas in acromegaly, the sex ratio is approximately balanced ((26), our series). Twenty of the 21 somatotroph silent tumours in our series were macroadenomas compared to $85 \%$ of macroadenoma in somatotroph tumours with acromegaly, which is consistent with the literature (27). As previously underlined, both SG (11) and plurihormonal subtypes, GH-PRL \pm TSH (6), showed greater frequency among the silent than the acromegaly-associated tumours. The diagnosis should be based not only on IHC for the hormones but also on the expression of the transcription factor Pit-1.

Considering just the 16 plurihormonal silent somatotroph tumours revealed differences in size and Ki-67 index: the silent tumours being larger $(P<0.001)$ with a higher Ki-67 index $(P=0.007)$. Clinical follow-up was available for 15 patients only and did not support the suspected bad prognosis of plurihormonal silent type 3 adenomas $(5,11)$. Indeed, only one patient presented tumour progression and was treated with gamma knife 6 years after initial surgery. However, we should underline that 3 patients underwent adjuvant radiotherapy, which can positively influence the prognosis. As suggested by others $(7,22,23)$, there is some evidence that such tumours may have clinically 'aggressive' behaviour. Only after a comparison of the long-term follow-up of two series with and without acromegaly can a poor prognosis of this subtype of tumour be defined.

The silent somatotroph tumours can be classified as differentiated tumours in the Pit-1-lineage (28) as they expressed GH-PRL $\pm \mathrm{TSH}, \mathrm{SSTR}_{2 \mathrm{~A}-5}$ and Pit-1. However, they are mostly SG with a significantly lower percentage of IR cells for Pit-1, GH and $\mathrm{SSTR}_{2 \mathrm{~A}}$ than is found in tumours with acromegaly. This would suggest that the silent somatotroph tumours might be less differentiated than those with acromegaly. They appear to correspond well with the 'silent subtype 3' described by Kovacs et al. (9).

The silent nature of these tumours may be explained by the low GH secretion of the somatotroph cells. In vitro, these silent tumours secrete small amounts of GH and respond to $\mathrm{GHRH}(5,6)$, but their level of secretion is very low, too low to induce elevated plasma levels of GH and IGF1 and clinical signs of acromegaly. 
For the management of silent somatotroph tumours, the first therapeutic option is surgery, especially when tumours are large and invasive $(5,19)$. The study of SSTR expression may be useful to identify those tumours susceptible to respond to SA treatment; however, no clinical data are available to demonstrate the effect of SA on silent somatotroph tumours.

\section{Conclusion}

The silent somatotroph tumours are Pit-1 lineage derivate tumours that appeared less differentiated than somatotroph tumour with acromegaly and must be studied separately from other non-functioning pituitary tumours. Additional clinicopathological studies are now needed to define the aggressiveness of these tumours and their responsiveness to surgical and pharmacological therapy.

\section{Declaration of interest}

The authors declare that there is no conflict of interest that could be perceived as prejudicing the impartiality of the research reported.

\section{Funding}

This research did not receive any specific grant from any funding agency in the public, commercial or not-for-profit sector.

\section{Acknowledgements}

The authors would like to thank Dr O Casar-Borota for helpful discussions and Emily Witty from AngloScribe for help with English proofing.

\section{References}

1 Horvath E, Kovacs K, Killinger DW, Smyth HS, Platts ME \& Singer W. Silent corticotropic adenomas of the human pituitary gland: a histologic, immunocytologic, and ultrastructural study. American Journal of Pathology 198098 617-638. PMID: 6244736 PMCID: PMC1903510.

2 Tourniaire J, Trouillas J, Chalendar D, Bonneton-Emptoz A, Goutelle A \& Girod C. Somatotropic adenoma manifested by galactorrhea without acromegaly. Journal of Clinical Endocrinology and Metabolism 198561 451-453. (doi:10.1210/jcem-61-3-451)

3 Chanson P, Raverot G, Castinetti F, Cortet-Rudelli C, Galland F, Salenave S \& French Endocrinology Society non-functioning pituitary adenoma work-group. Management of clinically non-functioning pituitary adenoma. Annales d'Endocrinologie 201576 239-247. (doi:10.1016/j.ando.2015.04.002)

4 Klibanski A, Zervas NT, Kovacs K \& Ridgway EC. Clinically silent hypersecretion of growth hormone in patients with pituitary tumors. Journal of Neurosurgery 198766 806-811. (doi:10.3171/ jns.1987.66.6.0806)

5 Kovacs K, Lloyd R, Horvath E, Asa SL, Stefaneanu L, Killinger DW \& Smyth HS. Silent somatotroph adenomas of the human pituitary. A morphologic study of three cases including immunocytochemistry, electron microscopy, in vitro examination, and in situ hybridization. American Journal of Pathology 1989134 345-353.

6 Trouillas J, Sassolas G, Loras B, Velkeniers B, Raccurt M, Chotard L, Berthezene F, Tourniaire J \& Girod C. Somatotropic adenomas without acromegaly. Pathology, Research and Practice 1991187 943-949. (doi:10.1016/S0344-0338(11)81065-4)

7 Sidhaye A, Burger P, Rigamonti D \& Salvatori SR. Giant somatotrophinoma without acromegalic features: more 'quiet' than 'silent': case report. Neurosurgery 200556 E1154; discussion E1154.

8 Wade AN, Baccon J, Grady MS, Judy KD, O'Rourke DM \& Snyder PJ. Clinically silent somatotroph adenomas are common. European Journal of Endocrinology 2011165 39-44. (doi:10.1530/EJE-11-0216)

9 Horvath E, Kovacs K, Smyth HS, Cusimano M \& Singer W. Silent adenoma subtype 3 of the pituitary-immunohistochemical and ultrastructural classification: a review of 29 cases. Ultrastructural Pathology 200529 511-524. (doi:10.1080/01913120500323514)

10 Erickson D, Scheithauer B, Atkinson J, Horvath E, Kovacs K, Lloyd RV \& Young WF Jr. Silent subtype 3 pituitary adenoma: a clinicopathologic analysis of the Mayo Clinic experience. Clinical Endocrinology 200971 92-99. (doi:10.1111/j.1365-2265.2008.03514.x)

11 Mete O, Gomez-Hernandez K, Kucharczyk W, Ridout R, Zadeh G, Gentili F, Ezzat S \& Asa SL. Silent subtype 3 pituitary adenomas are not always silent and represent poorly differentiated monomorphus plurihormonal Pit-1 lineage adenomas. Modern Pathology 201629 131-142. (doi:10.1038/modpathol.2015.151)

12 Trouillas J, Labat-Moleur F, Sturm N, Kujas M, Heymann MF, FigarellaBranger D, Patey M, Mazucca M, Decullier E, Verges B et al. Pituitary tumors and hyperplasia in multiple endocrine neoplasia type 1 syndrome (MEN1): a case-control study in a series of 77 patients versus 2509 non-MEN1 patients. American Journal of Surgical Pathology 200832 534-543. (doi:10.1097/PAS.0b013e31815ade45)

13 Chinezu L, Vasiljevic A, Jouanneau E, Francois P, Borda A, Trouillas J \& Raverot G. Expression of somatostatin receptors, SSTR $_{2 \mathrm{~A}}$ and $\mathrm{SSTR}_{5}$, in 108 endocrine pituitary tumors using immunohistochemical detection with new specific monoclonal antibodies. Human Pathology 201445 71-77. (doi:10.1016/j.humpath.2013.08.007)

14 Obari A, Sano T, Ohyama K, Kudo E, Qian ZR, Yoneda A, Rayhan N, Mustafizur Rahman M \& Yamada S. Clinicopathological features of growth hormone-producing pituitary adenomas: difference among various types defined by cytokeratin distribution pattern including a transitional form. Endocrine Pathology 200819 82-91. (doi:10.1007/ s12022-008-9029-z)

15 Trouillas J, Roy P, Sturm N, Dantony E, Cortet-Rudelli C, Viennet G, Bonneville JF, Assaker R, Auger C, Brue T et al. A new prognostic clinicopathological classification of pituitary adenomas: a multicentric case-control study of 410 patients with 8 years postoperative follow-up. Acta Neuropathologica 2013126 123-135. (doi:10.1007/s00401-013-1084-y)

16 Black PM, Hsu DW, Klibanski A, Kliman B, Jameson JL, Ridgway EC, Hedley-Whyte ET \& Zervas NT. Hormone production in clinically nonfunctioning pituitary adenomas. Journal of Neurosurgery 198766 244-250. (doi:10.3171/jns.1987.66.2.0244)

17 Yamada S, Sano T, Stefaneanu L, Kovacs K, Aiba T, Sawano S \& Shishiba Y. Endocrine and morphological study of a clinically silent somatotroph adenoma of the human pituitary. Journal of Clinical Endocrinology and Metabolism 199376 352-356. (doi:10.1210/ jc.76.2.352)

18 Furuhata S, Kameya T, Otani M, Shimamoto Y, Asada H \& Toya S. Silent mixed growth hormone cell-prolactin cell pituitary adenoma. Endocrine Pathology 19912 230-234. (doi:10.1007/BF02915213)

19 Naritaka H, Kameya T, Sato Y, Furuhata S, Otani M \& Kawase T. Morphological characterization and subtyping of silent somatotroph adenomas. Pituitary 19991 233-241. (doi:10.1023/A:1009942122673)

20 Sakharova AA, Dimaraki EV, Chandler WF \& Barkan AL. Clinically silent somatotropinomas may be biochemically active. Journal 
of Clinical Endocrinology and Metabolism 200590 2117-2121. (doi:10.1210/jc.2004-0875)

21 Mohammed S, Syro L, Abad V, Salehi F, Horvath E, Scheithauer BW, Kovacs K \& Cusimano M. Canadian Journal of Neurological Sciences 200936 123-125. (doi:10.1017/S0317167100006466)

22 Batisse M, Raverot G, Maqdasy S, Durando X, Sturm N, Montoriol PF, Kemeny JL, Chazal J, Trouillas J \& Tauveron I. Aggressive silent GH pituitary tumor resistant to multiple treatments, including temozolomide. Cancer Investigation 201331 190-196. (doi:10.3109/07 357907.2013.775293)

23 Chinezu L, Jouanneau E, Vasiljevic A, Trouillas J \& Raverot G. Silent GH pituitary tumor: diagnostic and therapeutic challenges. Annales d'Endocrinologie 201374 491-495. (doi:10.1016/j.ando.2013.09.003)

24 Cooper O \& Melmed S. Subclinical hyperfunctioning pituitary adenomas: the silent tumors. Best Practice and Research. Clinical Endocrinology and Metabolism 201226 447-460. (doi:10.1016/j. beem.2012.01.002)
25 Raverot G, Assié G, Cotton F, Cogne M, Boulin A, Dherbomez M, Bonneville JF \& Massart C. Biological and radiological exploration and management of non-functioning pituitary adenoma. Annales d'Endocrinologie 201576 201-209. (doi:10.1016/j.ando.2015.04.005)

26 Javorsky BR, Aron DC, Findling JW \& Tyrrell JB. Hypothalamus and pituitary gland. In Greenspan's Basic and Clinical Endocrinology, edn 9 , ch. 4, pp 65-114. Eds DG Gardner \& D Shoback. New York, NY, USA: McGraw Hill, 2011.

27 Potorac I, Petrossians P, Daly AF, Schillo F, Ben Slama C, Nagi S, Sahnoun M, Brue T, Girard N, Chanson P et al. Pituitary MRI characteristics in 297 acromegaly patients based on T2-weighted sequences. Endocrine Related Cancer 201522 169-177. (doi:10.1530/ ERC-14-0305)

28 Asa SL. The normal pituitary gland. In Tumors of the Pituitary Gland. AFIP Atlas of Tumor Pathology, edn Series 4, Fascicle 15, ch. 1, pp 1-35. Ed SG Silverberg. Washington, DC, USA: American Registry of Pathology Press, 2011.

Received 29 August 2016

Revised version received 28 October 2016

Accepted 15 November 2016 